\title{
Collaterals in portal hypertension: anatomy and clinical relevance
}

\author{
Hitoshi Maruyama, Shuichiro Shiina \\ Department of Gastroenterology, Juntendo University, Tokyo, Japan \\ Correspondence to: Hitoshi Maruyama. Department of Gastroenterology, Juntendo University, 2-1-1, Hongo, Bunkyo-ku, Tokyo 113-8421, Japan. \\ Email: h.maruyama.tw@juntendo.ac.jp.
}

\begin{abstract}
Portal hypertension is a key pathophysiology of chronic liver diseases typified with cirrhosis or noncirrhotic portal hypertension. The development of collateral vessels is a characteristic feature of impaired portal hemodynamics. The paraumbilical vein (PUV), left gastric vein (LGV), posterior gastric vein (PGV), short gastric vein (SGV), splenorenal shunt (SRS), and inferior mesenteric vein (IMV) are major collaterals, and there are some rare collaterals. The degree and hemodynamics of collateral may affect the portal venous circulation and may compensate for the balance between inflow and outflow volume of the liver. Additionally, the development of collateral shows a relation with the liver function reserve and clinical manifestations such as esophageal varices $(\mathrm{EV})$, gastric varices, rectal varices and the other ectopic varices, hepatic encephalopathy, and prognosis. Furthermore, there may be an interrelationship in the development between different collaterals, showing additional influences on the clinical presentations. Thus, the assessment of collaterals may enhance the understanding of the underlying pathophysiology of the condition of patients with portal hypertension. This review article concluded that each collateral has a specific function depending on the anatomy and hemodynamics and is linked with the relative clinical presentation in patients with portal hypertension. Imaging modalities may be essential for the detection, grading and evaluation of the role of collaterals and may help to understand the pathophysiology of the patient condition. Further investigation in a large-scale study would elucidate the basic and clinical significance of collaterals in patients with portal hypertension and may provide information on how to manage them to improve the prognosis as well as quality of life.
\end{abstract}

Keywords: Portal hypertension; cirrhosis; collateral; hepatic venous pressure gradient (HVPG); ultrasound (US); Doppler; esophageal varices (EV); gastric varices; ectopic varices; shunt; hepatic encephalopathy

Submitted Dec 02, 2020. Accepted for publication Mar 07, 2021.

doi: $10.21037 /$ qims-20-1328

View this article at: http://dx.doi.org/10.21037/qims-20-1328

\section{Introduction}

Chronic liver disease is an adult major disorder worldwide (1). There are many etiologies of chronic liver disease, viral hepatitis [hepatitis B virus (HBV) or hepatitis C virus (HCV)], alcohol abuse, primary biliary cholangitis, nonalcoholic steatohepatitis, and autoimmune hepatitis (2-6). However, irrespective of the reasons, the end stage is cirrhosis, which shows risk factors for developing hepatocellular carcinoma, and other complications such as ascites, icterus, gastroesophageal varices and hepatic encephalopathy (7-9).
Portal hypertension is a principal pathophysiology of cirrhosis and noncirrhotic portal hypertension (10). It is defined by the elevation of portal pressure, hepatic venous pressure gradient (HVPG) $>5 \mathrm{mmHg}$ (11). An HVPG of 10 to $12 \mathrm{mmHg}$ is the threshold level for the development of esophageal varices (EV), ascites, and the occurrence of variceal bleeding $(10,12)$, and an HVPG higher than $16 \mathrm{mmHg}$ suggests an increased risk of death $(13,14)$. Surgical resection of large malignant tumors (major liver resections) is generally contraindicated in patients with portal hypertension $(15,16)$. Moreover, an HVPG higher 


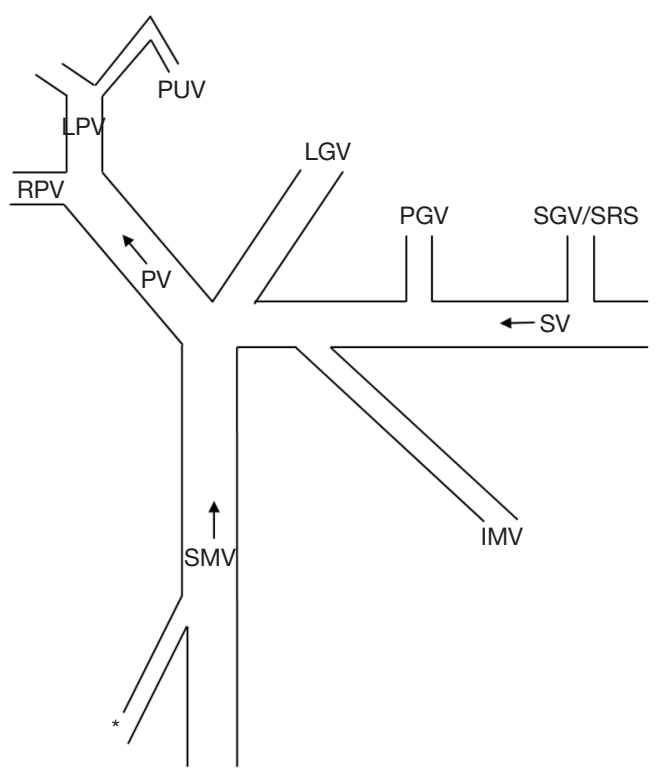

Figure 1 Schematic presentation of collaterals. *, shunt from SMV to right renal vein, duodenal varices, or stomal varices. PUV, paraumbilical vein; LGV, left gastric vein; PGV, posterior gastric vein; SGV, short gastric vein (with creating gastric varices); SRS, splenoreal shunt (without creating gastric varices); IMV, inferior mesenteric vein; $\mathrm{PV}$, portal vein; $\mathrm{SV}$, splenic vein; SMV, superior mesenteric vein.

than $20 \mathrm{mmHg}$ is the best independent prognostic marker for acute variceal bleeding (17-20) and thus indicates the presence of a much more severe status. The underlying mechanism of portal hypertension is the increased intrahepatic vascular resistance caused by hepatic fibrosis and/or the increased portal venous flow due to the elevated splanchnic blood flow (21-24). Splenomegaly caused by portal hypertension also accounts for the elevation of portal venous flow.

The development of collateral vessels is a characteristic feature of impaired portal hemodynamics. The paraumbilical vein (PUV), left gastric vein (LGV), posterior gastric vein (PGV), short gastric vein (SGV), splenorenal shunt (SRS), and inferior mesenteric vein (IMV) are major collaterals, and there are some rare collaterals. Each individual has their own pattern, single or combination of multiple collaterals. Imaging modalities, such as ultrasound (US), computed tomography (CT), and magnetic resonance imaging (MRI) are used for detection and grading. The degree and hemodynamics of the collateral may affect the portal venous circulation and may compensate for the balance between inflow and outflow volume of the liver. Furthermore, the development of the collateral shows a relation with the liver function reserve, and clinical manifestations such as EV, gastric varices, ectopic varices, hepatic encephalopathy and/or prognosis. Thus, the assessment of collaterals may enhance the understanding of the underlying pathophysiology of the condition of patients with portal hypertension. This review article focuses on the anatomy, clinical relevance and interrelationship of collateral vessels (except for cavernous transformation of the portal vein), summarizes the current concept and discusses the future directions of the research.

\section{PUV}

\section{Anatomy}

The PUV is a vessel in the falciform ligament that has been used as a fetal circulation. It develops at the hepatic surface side of the umbilical portion of the intrahepatic left portal vein and goes to the extrahepatic area, running toward the iliac vein (Figures 1,2). Almost one-third of the patients with the peri-umbilical collateral have multiple, not single vessels in the cohort of portal hypertension (25). The caput medusae is a unique appearance seen radiating from the umbilicus across the abdomen via epigastric veins. Dilatation of these abdominal veins could be observed in patients with severe portal hypertension through distended and engorged PUVs. However, it may also be present in clinical conditions such as inferior vena cava syndrome or superior vena cava syndrome with obstruction of the azygous system.

\section{Clinical significance}

The incidence of a patent PUV has been reported to be $11.1 \%$ (26), $15.6 \%$ (27), 26\% (28), 33.7\% (29), and $42 \%$ (30) in adult cirrhotic patients. Also, the studies demonstrated the increased flow volume in the portal trunk, which is the different point from the patients with extrahepatic collaterals. Although the reduced portal flow and advanced extrahepatic collaterals are reported as significant factors for developing portal vein thrombosis (31,32), the substantial effect of PUV for the suppression of portal vein thrombosis remains to be elucidated.

Investigators have shown the close relationship between the presence of patent PUV and worse liver function $(27,29)$. A more recent study reported that the mean flow volume 



Figure 2 Seventy-one-year-old male; HCV-related cirrhosis. (A) CT image showed PUV (arrows). (B) Percutaneous transhepatic portogram demonstrated development of PUV (arrows). HCV, hepatitis C virus; CT, computed tomography; PUV, paraumbilical vein.

in the portal trunk, incidence of the LGV with hepatofugal flow direction and the grade of $\mathrm{EV}$ were significantly higher in patients with a patent PUV $(908.2 \mathrm{~mL} / \mathrm{min} ; 70.2 \%$; and 9 with none to small vs. 27 with medium to large, respectively) than in those without $(771.7 \mathrm{~mL} / \mathrm{min} ; 48.5 \%$; and 57 with none to small vs. 48 with medium to large, respectively) (28). The HVPG and wedged hepatic venous pressure $\left(\mathrm{mmH}_{2} \mathrm{O}\right)$ were significantly higher in the former (268.0 \pm 89.7 and $389.5 \pm 99.9$, respectively) than in the latter (203.5 \pm 63.2 and $317.7 \pm 67.7$, respectively). Furthermore, the deterioration of ascites in the 2-year period was significantly more frequent in patients with a patent PUV (4/12, 33.3\%) than in those without. The published data strongly suggest that a patent PUV appears to be a sign of pressure-loaded portal hemodynamics in cirrhotic patients. Although a patent PUV may result in an underestimation of the degree of portal hypertension because of less reduction of portal trunk blood flow, the clinician needs to be aware of the worse condition of the patients.

\section{LGV}

\section{Anatomy}

The LGV runs in the small omentum along the lesser curvature of the stomach, showing a coronary shape, and connects to the portal system at the portal splenic angle, portal trunk or splenic vein. Thus, clinically, the LGV and the coronary vein are treated as equivalent. It shows close connection with systemic circulation at the esophagogastric junction and/or around the esophagus through the azygos vein or accessory hemiazygos vein.

A recent clinical study in 1,325 patients with gastric cancer who underwent radical resection analyzed the intraoperative vascular anatomy and reported five types of LGV drainage patterns: type 1 with the LGV passed to the ventral side of the splenic artery and common hepatic artery in 743 patients (56.1\%), type 2 with the LGV at the dorsal side of the common hepatic artery in 550 patients (41.5\%), type 3 with the LGV at the dorsal side of the splenic artery in 4 patients $(0.3 \%)$, type 4 with the LGV along the hepatogastric ligament, draining directly into the liver in 21 patients (1.6\%), and type 5 with the negative LGV and the right gastric vein was enlarged in 7 patients (0.5\%) (33). Endoscopic ultrasonography (EUS)-based analysis has demonstrated the detailed anatomy of the peripheral branching in patients with portal hypertension; LGV bifurcates into anterior and posterior branches, the former goes to $\mathrm{EV}$ (Figures 1,3) and the latter goes to the paraesophageal vein (Figures 1,4) (34). However, as the study was performed in cases with gastric cancer, it should be noted that the anatomical feature may not necessarily be applied to the patients with portal hypertension.

\section{Clinical significance}

The LGV shows hepatopetal flow direction in the normal subjects, as the role is to collect the blood flow from the upper stomach and to drain it into the portal system (Figures 1,5). 

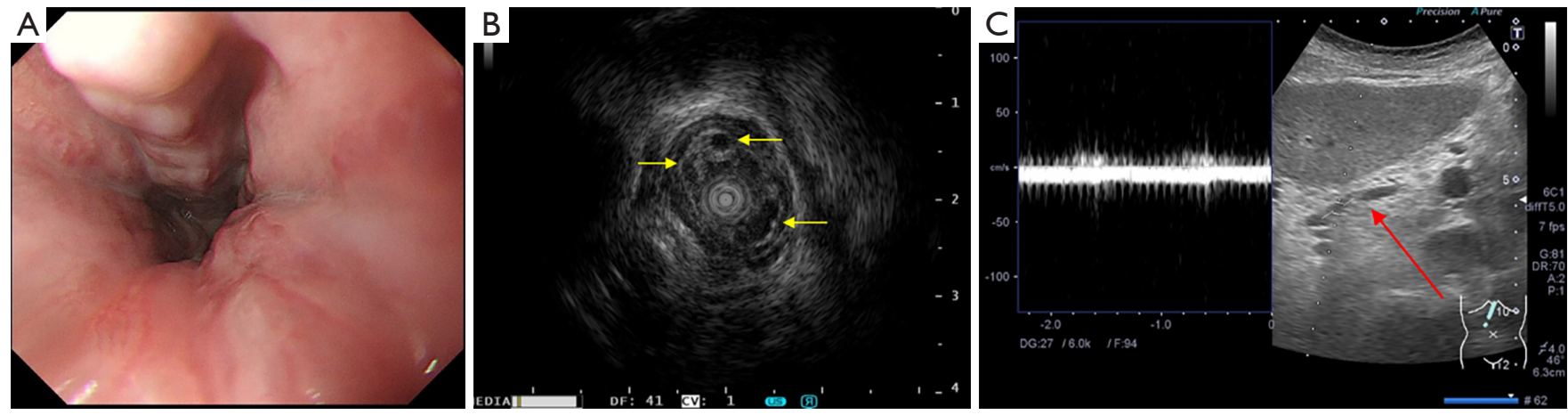

Figure 3 Seventy-five-year-old male, nonBnonC cirrhosis with EV. (A) Moderate-degree of EV. (B) Ultrasonic microprobe (12 MHz) demonstrated submucosal vessels (arrows) corresponding to EV. (C) Pulsed Doppler sonography demonstrated LGV with hepatofugal flow direction (arrow). EV, esophageal varices; LGV, left gastric vein.
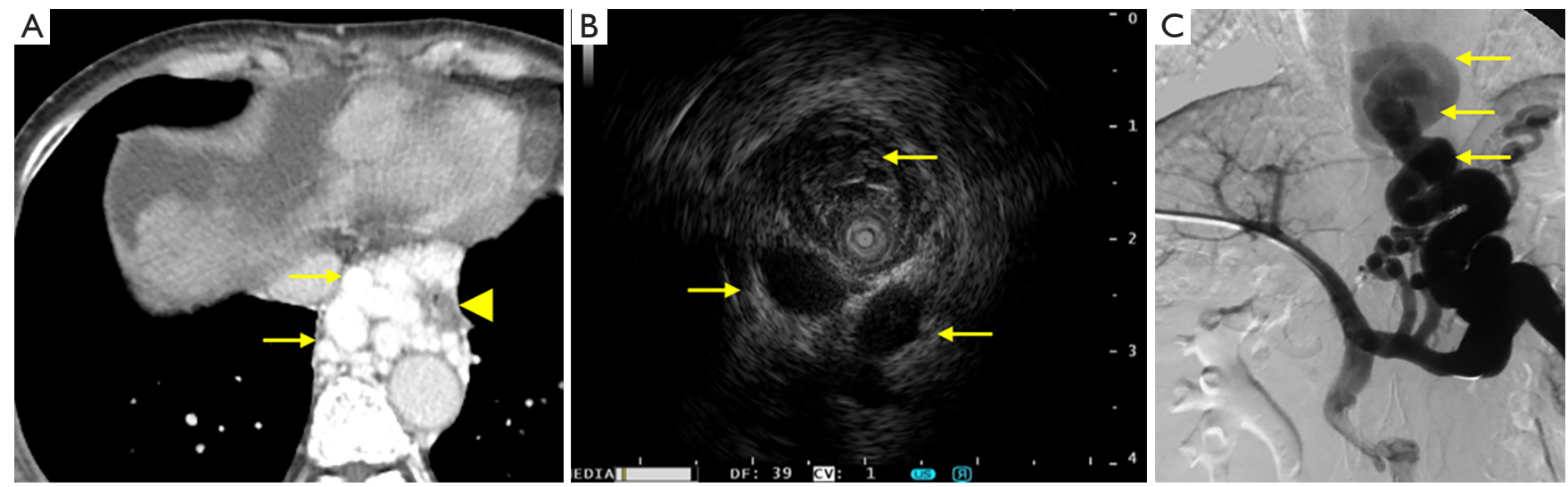

Figure 4 Seventy-seven-year-old female, nonBnonC cirrhosis (A) CT image showed development of paraesophageal vein (arrows) around the esophagus (arrow head). (B) Ultrasonic microprobe $(12 \mathrm{MHz}$ ) demonstrated paraesophageal vein (arrows) around the esophagus. (C) Percutaneous transhepatic portogram demonstrated development of paraesophageal vein (arrows). CT, computed tomography.

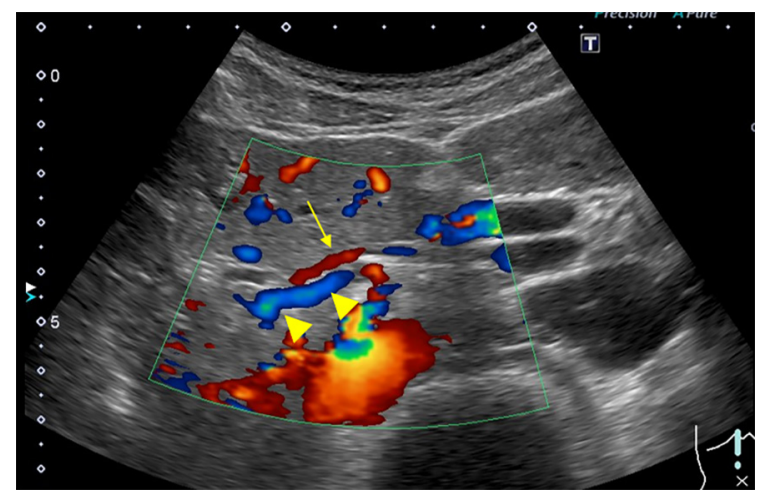

Figure 5 Doppler sonogram (normal subject, 42-year-old male) demonstrated LGV (arrow) with hepatopetal flow direction. Arrow heads, left gastric artery. LGV, left gastric vein.
However, in cases of portal hypertension, the flow direction of the LGV changes in a hepatofugal manner, and the LGV acts as a major pathway that brings portal blood flow into the $\mathrm{EV}$ and/or paraesophageal vein via the upper stomach (35). Therefore, it is the vessel which is present in healthy people as well as patients with portal hypertension.

Transabdominal US examination has shown $89.6 \%$ detectability of the LGV in cirrhosis patients with $\mathrm{EV}$, and $87.6 \%$ of the LGV showed hepatofugal flow direction (36). Furthermore, the positive detection of the LGV showed $100 \%$ sensitivity and negative predictive value (NPV) to identify large EVs. The best cutoff value in the LGV diameter was $5.35 \mathrm{~mm}$ to identify large EVs, showing an area under the receiver operating characteristic curve 


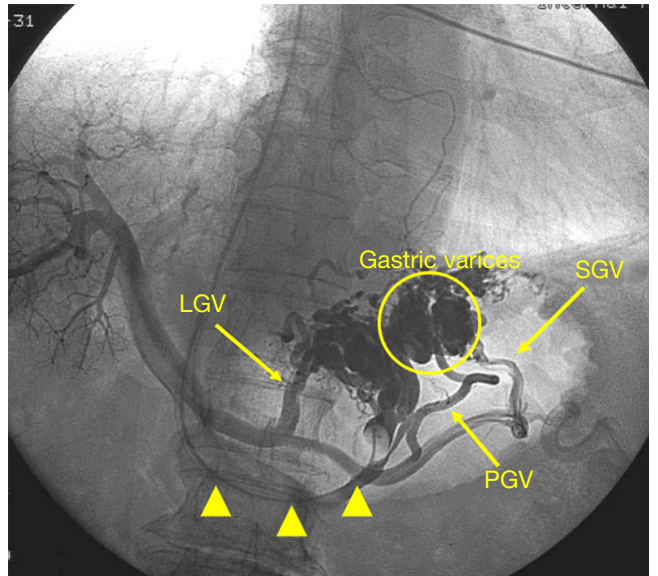

Figure 6 Sixty-nine-year-old male, HBV-related cirrhosis with gastric varices. Transjugular retrograde venography by using balloon catheter (arrow heads) demonstrated gastric varices (circle) and three inflow routes, LGV, PGV and SGV. The PGV originates from the middle of splenic vein. HBV, hepatitis B virus; LGV, left gastric vein; PGV, posterior gastric vein; SGV, short gastric vein.

(AUROC) of 0.753 with $90 \%$ sensitivity and $96.5 \%$ NPV.

The study performed earlier reported that the velocity in the LGV by transabdominal Doppler US was associated with the development of $\mathrm{EV}$ and bleeding risk (37). In the study using EUS, the branch pattern of the LGV was more likely to be anterior branch dominant $(\mathrm{P}=0.041)$, according to the enlargement of the variceal size (34). Additionally, another EUS-based study has shown lower hepatofugal flow velocity in the LGV trunk and a lower incidence of the anterior branch dominant type in therapeutic responders (38). These data strongly suggest the close linkage between LGV hemodynamics and the degree of $\mathrm{EV}$ and, therefore, US-based assessment (transabdominal/EUS) of the LGV is important in the noninvasive evaluation of the clinical severity of EV.

The LGV with hepatofugal flow direction also affect the development of hepatic encephalopathy, due to an aspect of portosystemic shunt, with or without creating EV (39-42). However, an actual incidence and clinical influence of LGVrelated encephalopathy remains undetermined.

The portal hemodynamic response caused by vasoactive substances is another target of clinical research in patients with EV. A unique study using intravenous injection of glucagon $(1 \mathrm{mg})$, which is known as a causative or modulating factor of splanchnic hyperemia in portal hypertension and chronic liver diseases (43), reported that an increase in flow velocity in the LGV that is due to glucagon depends on the degree of EV (44). Furthermore, a blunted response to vasoactive substances seems to be a hemodynamic feature of the LGV in patients with large EV and advanced portal hypertension, suggesting an implication for the mechanism of vasoactive substances in patients with portal hypertension and EV. Whenever there is grade 4 portal vein thrombosis (complete thrombosis of portal vein and proximal and distal superior mesenteric vein) and this is not accompanied by a large SRS, but the LGV is very large, the portal vein of the liver allograft may be anastomosed to the LGV of the recipient (45).

\section{PGV}

\section{Anatomy}

The PGV is the collateral situated between the LGV and the SGV, originating from the middle of the splenic vein (Figures 1,6), and runs posteriorly along the stomach wall. It drains into the $\mathrm{EV}(81 \%)$ and into the left renal vein (23\%) in patients with portal hypertension (46).

\section{Clinical significance}

The portogram-based study reported a $42 \%$ relative incidence of $\mathrm{PGV}$ in patients with portal hypertension, with forming communication to the left renal vein in $23 \%$ of cases (46). It showed a close relationship with the presence of $\mathrm{EV}(81 \%)$, gastric varices $(23 \%)$, and the presence of hepatic encephalopathy (23\%) (46). However, the physiological hemodynamics and clinical relevance of PGV remain to be elucidated because no study using Doppler US has been performed, probably because of the difficulty of detection by US.

\section{SGV}

\section{Anatomy}

The SGV is a collateral (usually including multiple vessels) that develops at the splenic hilum. It runs traversing the gastrosplenic ligament and drains the fundus and the left part of the greater curvature of the stomach.

\section{Clinical significance}

A previous study performed on percutaneous portography reported the relative frequency of collaterals in patients with portal hypertension, SGV with $34 \%$ incidence following 

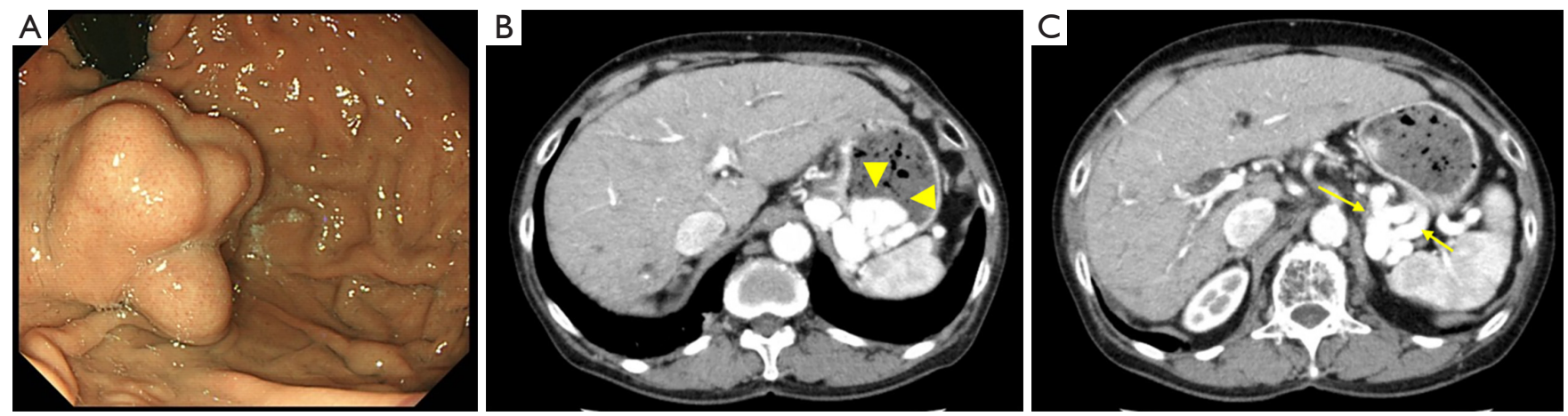

Figure 7 Sixty-two-year-old female, alcoholic cirrhosis with gastric varices. (A) Moderate-degree of gastric fundal varices. (B) Gastric fundal varices (arrow heads). (C) SGV as the inflow route to gastric varices (arrows). SGV, short gastric vein.

LGV with $90 \%$ and PGV with $42 \%$ (46). A study using US in cirrhosis patients reported an 86/233 (36.9\%) incidence of SGV (corresponding to shunt vessel that runs cranial side), whose mean diameter was $6.4 \pm 2.3$ (range, 2.6-13.1) mm and flow velocity was $11.2 \pm 6.7$ (range, 4-44.1) cm/s (47). There is a close relationship between the presence of gastric fundal varices and SGV [44/86 (51.2\%) with gastric varices] (Figures 1,7) (47), and the hemodynamics on Doppler US may be predictive of risky gastric varices; diameter, flow velocity and flow volume of SGV were significantly greater in bleeders $(9.6 \pm 3.1 \mathrm{~mm}, 11.4 \pm 5.2 \mathrm{~cm} / \mathrm{s}, 499 \pm 250.1 \mathrm{~mL} / \mathrm{min})$ than non-bleeders $(6.5 \pm 2.2 \mathrm{~mm}, \mathrm{P}=0.0141 ; 7.9 \pm 3.3 \mathrm{~cm} / \mathrm{s}$, $\mathrm{P}=0.022 ; 205 \pm 129.1 \mathrm{~mL} / \mathrm{min}, \mathrm{P}=0.0031$ ) (48). In addition, the advanced hemodynamics in the SGV may affect the flow direction of the splenic vein, resulting in the non-forward (reversed or to-and-fro), which showed a higher cumulative bleeding rate $(38.8 \%$ at 3 years, $59.2 \%$ at 5 years) than in patients with forward splenic vein flow $(18.7 \%$ at 3 years, $32.2 \%$ at 5 years, $\mathrm{P}=0.0199$ ) (48).

Since the SGV also has a role as a portosystemic shunt, there is a certain relationship between the presence of the SGV and hepatic encephalopathy $(46,47,49,50)$. However, the incidence of hepatic encephalopathy seems lower in case with the SGV than that with the SRS (47).

\section{SRS}

\section{Anatomy}

The SRS is a collateral demonstrated at the splenic hilum, acting as a connection between splenic vein and left renal vein. For the collaterals at the splenic hilum, in general, the SRS is defined for shunt without creating gastric varices, and the SGV is defined for that with creating gastric varices (47).

\section{Clinical significance}

The relative incidence of SRS is reported to be $7 \%$ in patients with portal hypertension by using portography (46) and $10.7 \%$ (all with hepatofugal flow direction) in cirrhosis by using transabdominal US (47).

The presence of SRS may enhance the risk of chronic hepatic encephalopathy (51). The study performed later also reported that the degree of hepatic encephalopathy was significantly worse in patients with collateral at the splenic hilum on the caudal side (almost SRS, $\mathrm{P}=0.0047$ ) than in those with collateral at the splenic hilum on the cranial side (almost SGV) (47).

Another study performed in 153 cirrhosis patients showed that patients with hyponatremia $(\mathrm{Na}<135 \mathrm{mEq} / \mathrm{L})$ had a significantly greater frequency of possessing an SRS (SRS; $\mathrm{P}=0.0068$ ) (52). Additionally, serum sodium concentrations were significantly lower in patients with SRS than in those without SRS $(\mathrm{P}=0.0193)$. The cumulative survival rate was significantly worse in patients with both hyponatremia and SRS ( $20 \%$ at 1 year). These data strongly suggest the negative influence of SRS on the liver function reserve and prognosis in cirrhosis. Whenever there is complete obstruction of the portal vein by thrombosis, every attempt should be performed to accomplish complete removal of the thrombus. Whenever there is grade 4 portal vein thrombosis (complete thrombosis of portal vein and proximal and distal superior mesenteric vein) and this is accompanied by a large SRS, the left renal vein may be ligated next to the confluence with the inferior vena cava and a renoportal bypass using a venous graft may be created 


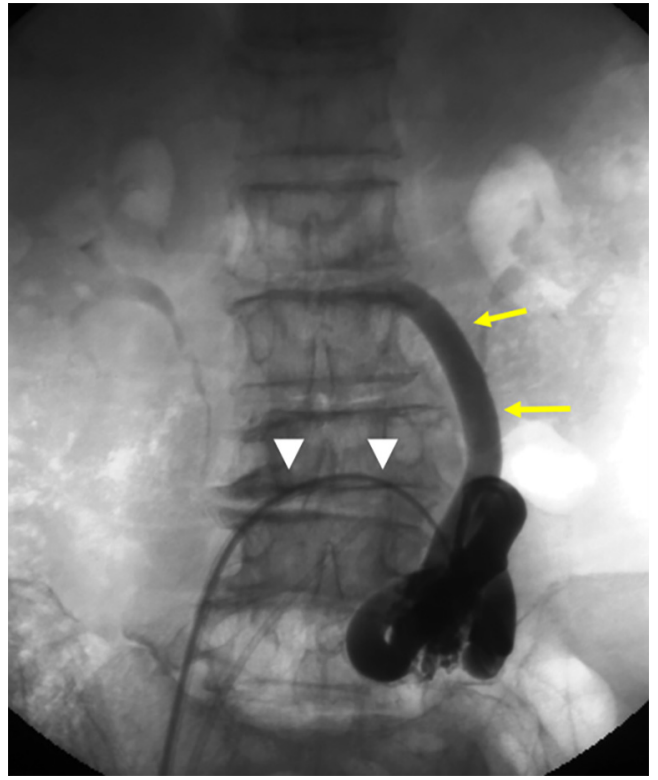

Figure 8 Sixty-seven-year-old female, HCV-related cirrhosis with hepatic encephalopathy. Transfemoral retrograde venography by using balloon catheter (arrow heads) demonstrated IMV (arrows). Splenic vein is the route for which the IMV drains. HCV, hepatitis $C$ virus; IMV, inferior mesenteric vein.

to perfuse the portal vein of the liver allograft during liver transplantation surgery (53-55).

\section{IMV}

\section{Anatomy}

The IMV is the vessel that runs anterior to the sacrum and toward the upper abdomen, passing posterior to the distal duodenum and anterior to the left renal vein and the superior mesenteric artery before communicating with the portal system. The main route in the portal system for which the IMV drain is the splenic vein (Figures 1,8), followed by the superior mesenteric vein or the splenomesenteric confluence. The distal area whose blood flow is covered by IMV is from the distal transverse colon to the proximal rectum (56). Actually, it has often been used as a route to decompress portal pressure by surgical treatment (57).

\section{Clinical significance}

The IMV is a common vessel that is detected in more than $90 \%$ of CT images $(58,59)$, and the incidence and diameter of the IMV were similar between the control and cirrhosis groups (60).

Peripheral branches of the IMV with hepatofugal flow direction are closely related to the development of rectal varices, characterized by the collaterals between superior rectal veins and middle to inferior rectal veins of the iliac venous route. The incidence of rectal varices is $35 \%$ to $59.9 \%$ in cirrhosis and $89 \%$ in noncirrhotic portal hypertension, depending on the patient population (61-65).

There seems to be no relationship between Child's grade, the grade of $\mathrm{EV}$, the presence of gastric varices, portal hypertensive gastropathy, or whether patients received sclerotherapy and the development of anorectal varices (65). The HVPG of cirrhotic patients with anorectal varices was similar to that of cirrhotic patients without anorectal varices $(14 \pm 6 \mathrm{mmHg}, \mathrm{n}=22$, vs. $16 \pm 7 \mathrm{mmHg}, \mathrm{n}=39, \mathrm{P}>0.05)$. Additionally, the prevalence of anorectal varices in cirrhotic patients had no relation to ascites (64). The presence of the red sign on rectal varices may suggest a high-risk condition for bleeding; however, the detailed pathophysiology of bleeding risk has not been clarified (66).

A more recent clinical study performed in 467 cirrhosis patients demonstrated hemodynamics in the IMV using Doppler US; $20.1 \%$ detectability of IMV showed hepatopetal flow in 51, hepatofugal flow in 33 and to and fro in 10 (67). Patients with IMV with hepatofugal flow showed more severe ascites $(\mathrm{P}=0.006)$, more severe Child's grade $(\mathrm{P}=0.004)$, higher incidence of decompensated condition of the liver $(17 / 33,51.5 \%$ vs. $14 / 51,27.5 \% ; \mathrm{P}=0.015)$, and more frequent rectal varices $(9 / 16,56.3 \%$ vs. $2 / 15,13.3 \% ; \mathrm{P}=0.013)$ than the patients who had IMV with a hepatopetal flow direction. However, the incidence of gastroesophageal varices was lower in patients who had IMV with hepatofugal flow $(17 / 33,51.5 \% ; \mathrm{P}=0.005)$ or to and fro $(4 / 10,40 \% ; \mathrm{P}=0.008)$ than IMV with hepatopetal flow $(41 / 51,80.4 \%)$ (67). The study suggested two opposite effects of IMV in cirrhosis: a deteriorating effect that promotes rectal varices and hepatic encephalopathy and an ameliorating effect that reduces the chance of gastroesophageal varices.

\section{Other types of rare collaterals}

\section{Retroperitoneal collaterals}

Collaterals may rarely occur in the retroperitoneum, and duodenal varices are one of them, with an incidence of $0.4 \%$ in patients with portal hypertension (68). The duodenal varices present in the submucosal layer of the posterior wall of the duodenum with the superior/inferior pancreaticoduodenal 

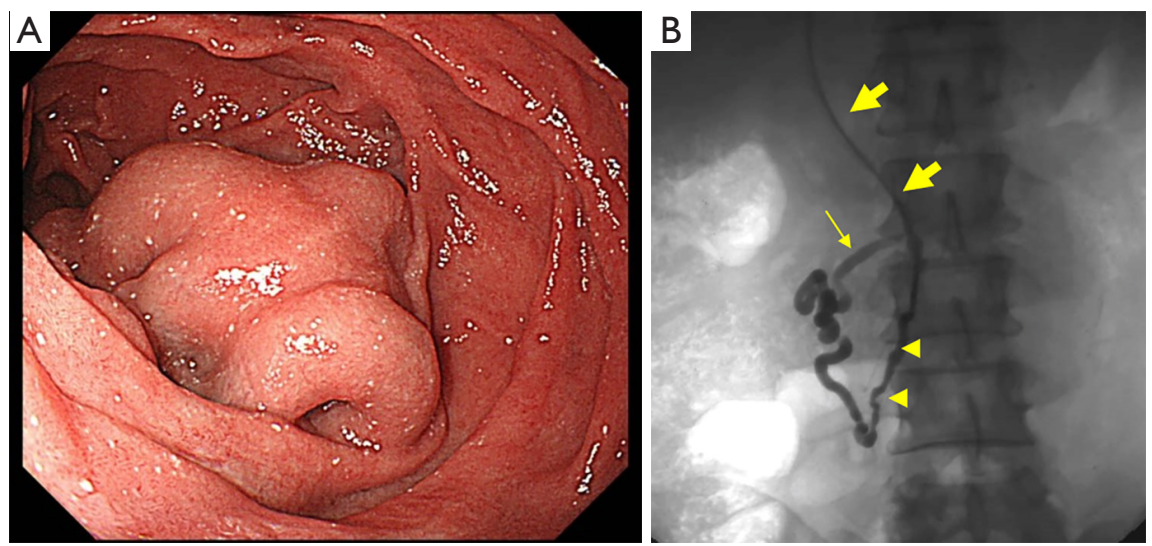

Figure 9 Fifty-eight-year-old male, HCV-related cirrhosis. (A) Duodenal varices. (B) Transjugular venogram demonstrated inferior pancreaticoduodenal vein (arrow) as inflow route, and the outflow route (arrow heads) which connects to inferior vena cava. Thick arrows, catheter in the inferior vena cava. $\mathrm{HCV}$, hepatitis $\mathrm{C}$ virus.
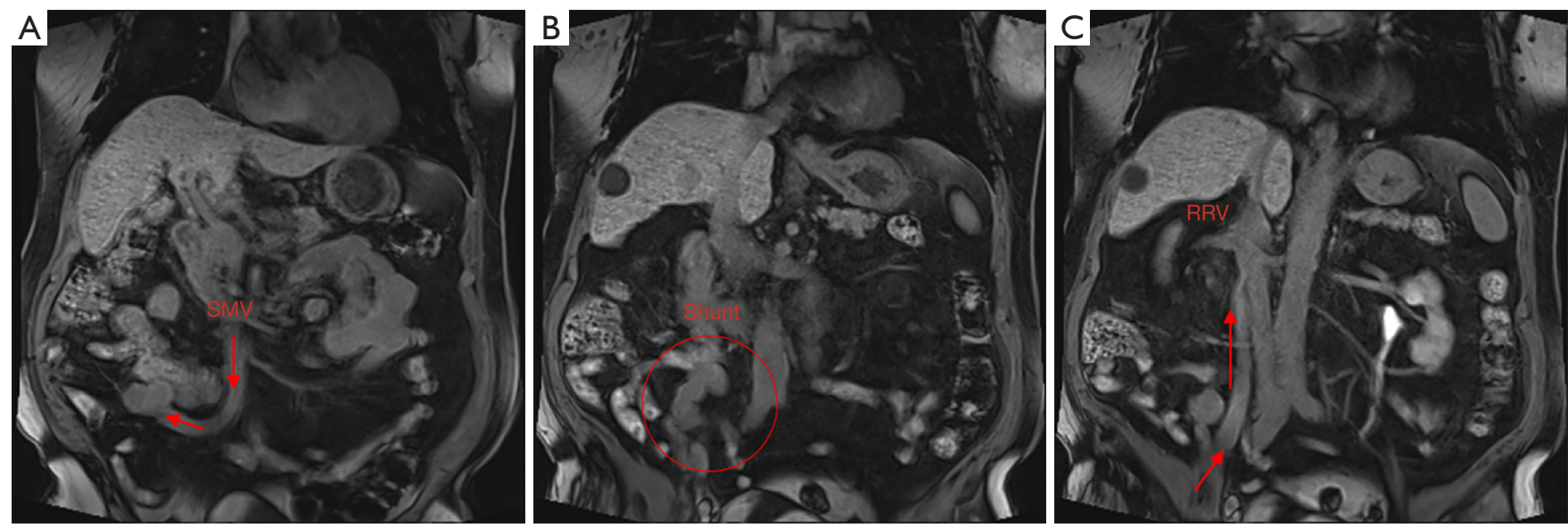

Figure 10 Eighty-eight-year-old male, nonalcoholic steatohepatitis, cirrhosis. (A) Collateral (arrows) which originates from superior mesenteric vein. (B) Shunt showing tortuous shape. (C) Outflow route (arrows) which connects with RRV. SMV, superior mesenteric vein; RRV, right renal vein.

vein originating in the portal vein trunk and/or superior mesenteric vein as the inflow route and the inferior vena cava as the outflow route (Figures 1,9). Although there are many treatment options using endoscopy, interventional radiology and surgical procedures, the definitive management direction of duodenal varices has not been determined (69).

\section{Collateral which drains into the right renal vein (RRV)}

Collateral drainages into the RRV is very rare, and there are only several case reports. The other side of the collateral is the portal vein $(70,71)$ or superior mesenteric vein (Figures 1,10 )
(72-74). Severe liver function typified with chronic hepatic encephalopathy and/or ascites is the characteristic feature of the patients. Further investigation with a larger cohort may be needed to determine the actual incidence, clinical significance and appropriate management of this type of collateral.

\section{Stomal varices}

Stomal varices is a relative rare condition, which account for $5 \%$ of variceal bleeding (75). The most common story may be the occurrence in patients with ileostomies after 
proctocolectomy for inflammatory bowel disease with associated primary sclerosing cholangitis. As with the other varices, it is related to the collateral development, branch of superior mesenteric vein (76), or that of IMV (77), in post-colectomy patients with portal hypertension. It is considered as a treatment resistive condition because the threshold portal pressure gradient leading to bleeding may be lower than for $\mathrm{EV}$ or gastric varices (78).

\section{Comprehensive discussion and future prospective}

\section{Reopening of the embryonic venous channel and spontaneous shunt}

There is no report regarding the presence of the following collaterals in normal subjects: PUV, SRS, PGV, and SGV; therefore, the detection of these vessels may suggest the presence of portal hypertension. However, the LGV and the IMV are vessels that are also present in normal subjects. A previous study using Doppler US reported the presence of LGV with hepatopetal flow direction in 39 healthy adults (37). For the IMV, the diameter measured behind or to the left of the duodenojejunal flexure was 3-6 mm (mean \pm standard deviation, $3.9 \pm 0.83 \mathrm{~mm}$ ) in 14 normal cases (79), and portal hypertension was suggested when the diameter of the IMV was $9 \mathrm{~mm}$ or more. Anatomy of the IMV in normal subjects is well described by multidetector CT (80), and the IMV with hepatopetal flow direction by Doppler US in normal subjects is clearly demonstrated (56). Therefore, in a precise sense, an identification of the LGV or the IMV as the collateral caused by portal hypertension may be determined by the assessment of flow direction in the vessels, and Doppler US may be an essential tool for this purpose with the possible evaluation of physiological hemodynamics. Furthermore, these two collaterals may not be classified as spontaneous shunts when they are defined by the reopening of the embryonic venous channel.

\section{Influence of collateral on the intrabepatic blood flow or other collaterals}

Development of collateral provides steal of blood flow which should be into the liver, and this phenomenon accounts for the worse condition of the patients. The negative influence may be explained by the improved shunt patency of transjugular intrahepatic portosystemic shunt by adding coronary vein embolization (81). It is also supported by the data that the ligation of left renal vein to control SRS is effective even after liver transplantation $(82,83)$. In addition, the improvement of hepatic encephalopathy after the embolization of collateral with balloon-occluded retrograde obliteration may enhance the benefit of the control of collateral hemodynamics in patients with portal hypertension $(49,84)$.

Meanwhile, the development of collaterals may affect the hemodynamics of other collaterals, resulting in changes in clinical manifestations.

For the development of varices, the presence of an SRS may have a role in suppressing the formation of gastroesophageal varices but without reducing the risk of bleeding. Similar data are reported in the study regarding IMV; the incidence of gastroesophageal varices was lower in patients who had IMV with hepatofugal flow or to and fro than IMV with hepatopetal flow (67).

However, there is an argument that there is no significant relationship between the presence of SRS and degree/ bleeding of $\mathrm{EV}$ (85) and no difference in the incidence of rectal varices between cirrhosis patients with and without EV (65). Meanwhile, it has been reported that a large EV was detected more frequently in patients with SRS than in those without SRS (86), and a higher incidence of LGV with hepatofugal flow direction and grade of EV was demonstrated in patients with a patent PUV (67). Therefore, the interrelation influence between different collaterals may depend on the type, pattern and degree of collaterals.

\section{Summary of imaging techniques for the evaluation of portal system and collaterals}

There are many imaging modalities to assess the hemodynamics in the portal system and collaterals (Table 1). Firstline approach may be, undoubtedly, US with the advantage of almost no invasiveness and real-time observation. However, operator-, and patient-dependency may be linked to the low reproducibility and objectivity of US, while CT/MRI may have the advantage in this regard. A major indication of US, CT, and MRI to assess the hemodynamics of collateral is to detect blood flow, to evaluate the flow direction, and to measure the velocity/flow volume by using Doppler US method.

Interventional technique using catheter may provide more detailed investigation; portogram by arteriography, hepatic venous catheterization and percutaneous transhepatic portography (PTP). The latter two methods may be the standard for the assessment of portal hemodynamics, the 
Table 1 Summary of imaging techniques for the evaluation of portal system and collaterals

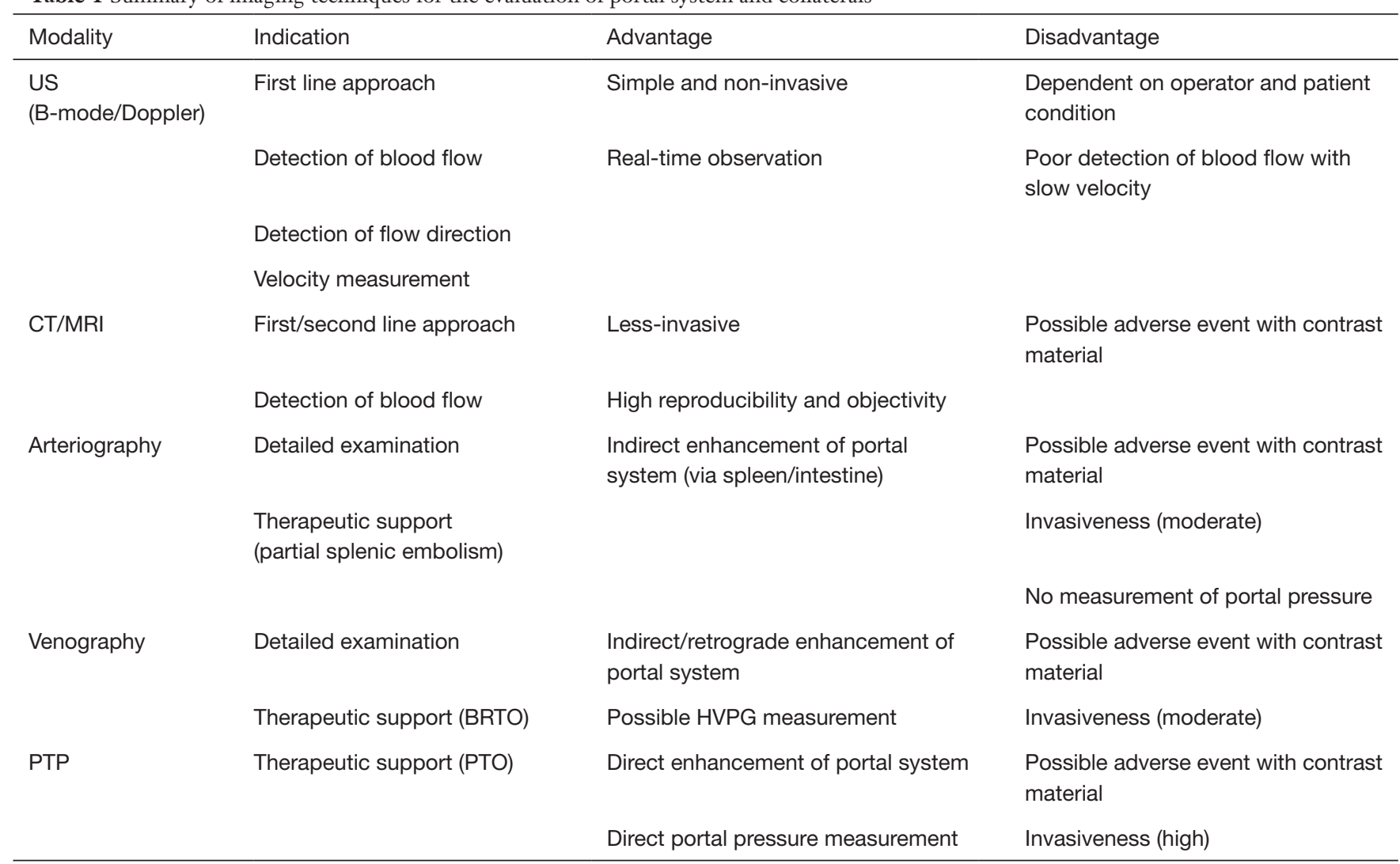

US, ultrasound; CT, computed tomography; MRI, magnetic resonance imaging; PTP, percutaneous transhepatic portography; BRTO, balloon-occluded retrograde transvenous obliteration; HVPG, hepatic venous pressure gradient; PTO, percutaneous transhepatic obliteration.

former for HVPG and the latter for direct measurement of portal pressure. The real-world indication of these procedures may be therapeutic support except for research purpose, arteriography for partial splenic embolism, hepatic venous catheterization when performing balloon-occluded retrograde obliteration, and PTP for portal obstruction.

As for the advanced technology, share wave elastography (possible evaluation of liver/spleen stiffness with realtime observation even in patients with ascites), which is available for noninvasive prediction of the severity of portal hypertension and EV (87-89). However, it is an indirect assessment and lower specificity may be the disadvantage. Xenon CT shows quantitative assessment of hepatic tissue blood flow as well as arterial/portal venous flow (90). Fourdimensional flow MRI is also available to evaluate portal hemodynamics by using volumetric acquisition technique (91-93). However, time/spatial resolution and simplicity are not satisfactory with CT/MRI, which may be hard to be used as a common tool. Taken together, ideal imaging tool may not be present at this time, and multiple modalities need to be selected according to the patient condition and the availability of the adequate resources and expertise.

\section{Future direction of the research for collaterals}

Based on the analysis with a specific single collateral vessel, there seems to be no linkage between the prognosis and the development of collateral, PUV (28), SRS (52) and IMV (67). However, a recent clinical study including 1,729 patients reported the relationship between poor prognosis and the development of collateral (irrespective of the kind of collateral) (94). The underlying pathophysiology related to the unfavorable outcome of patients with collaterals needs to be clarified, and additional studies are necessary to determine whether intervention for collateral embolization may have a survival benefit (95). Another aspect is the paucity of the data regarding the role and influence of collaterals in the early stage of portal hypertension. Furthermore, criteria 
and optimal imaging modality to determine the severity of collaterals should be discussed for the standard assessment.

\section{Conclusions}

Each collateral has a specific function depending on the anatomy and hemodynamics and is linked with the relative clinical presentation in patients with portal hypertension. Imaging modalities may be essential for the detection, grading and evaluation of the role of collaterals and may help to understand the pathophysiology of the patient condition. Further investigation in a large-scale study would elucidate the basic and clinical significance of collaterals in patients with portal hypertension and may provide information about how to manage them to improve the prognosis as well as quality of life.

\section{Acknowledgments}

Funding: None.

\section{Footnote}

Conflicts of Interest: Both authors have completed the ICMJE uniform disclosure form (available at http://dx.doi. org/10.21037/qims-20-1328). The authors have no conflicts of interest to declare.

Ethical Statement: The authors are accountable for all aspects of the work in ensuring that questions related to the accuracy or integrity of any part of the work are appropriately investigated and resolved. This article does not contain any studies with human participants performed by any of the authors.

Open Access Statement: This is an Open Access article distributed in accordance with the Creative Commons Attribution-NonCommercial-NoDerivs 4.0 International License (CC BY-NC-ND 4.0), which permits the noncommercial replication and distribution of the article with the strict proviso that no changes or edits are made and the original work is properly cited (including links to both the formal publication through the relevant DOI and the license). See: https://creativecommons.org/licenses/by-nc-nd/4.0/.

\section{References}

1. Byass P. The global burden of liver disease: a challenge for methods and for public health. BMC Med 2014;12:159.

2. Razavi H. Global epidemiology of viral hepatitis. Gastroenterol Clin North Am 2020;49:179-89.

3. WHO Global hepatitis report 2017. Geneva: World Health Organization, 2017.

4. Spearman CW, Dusheiko GM, Hellard M, Sonderup M. Hepatitis C. Lancet 2019;394:1451-66.

5. Sheka AC, Adeyi O, Thompson J, Hameed B, Crawford PA, Ikramuddin S. Nonalcoholic steatohepatitis: a review. JAMA 2020;323:1175-83.

6. Eslam M, Newsome PN, Sarin SK, Anstee QM, Targher G, Romero-Gomez M, Zelber-Sagi S, Wai-Sun Wong V, Dufour JF, Schattenberg JM, Kawaguchi T, Arrese M, Valenti L, Shiha G, Tiribelli C, Yki-Järvinen H, Fan JG, Grønbæk H, Yilmaz Y, Cortez-Pinto H, Oliveira CP, Bedossa P, Adams LA, Zheng MH, Fouad Y, Chan WK, Mendez-Sanchez N, Ahn SH, Castera L, Bugianesi E, Ratziu V, George J. A new definition for metabolic dysfunction-associated fatty liver disease: an international expert consensus statement. J Hepatol 2020;73:202-9.

7. Tsochatzis EA, Bosch J, Burroughs AK. Liver cirrhosis. Lancet 2014;383:1749-61.

8. Kulik L, El-Serag HB. Epidemiology and management of hepatocellular carcinoma. Gastroenterology 2019;156:477-91.e1.

9. Ge PS, Runyon BA. Treatment of patients with cirrhosis. N Engl J Med 2016;375:767-77.

10. Garcia-Tsao G, Abraldes JG, Berzigotti A, Bosch J. Portal hypertensive bleeding in cirrhosis: Risk stratification, diagnosis, and management: 2016 practice guidance by the American Association for the study of liver diseases. Hepatology 2017;65:310-35.

11. Bosch J. Portal hypertension and cirrhosis: from evolving concepts to better therapies. Clin Liver Dis (Hoboken) 2020;15:S8-12.

12. Turon F, Casu S, Hernandez-Gea V, Garcia-Pagán JC. Variceal and other portal hypertension related Bleeding. Best Pract Res Clin Gastroenterol 2013;27:649-64.

13. Bosch J, Garcia-Pagan JC, Berzigotti A, Abraldes JG. Measurement of portal pressure and its role in the management of chronic liver disease. Semin Liver Dis 2006;26:348-62.

14. Bosch J, Abraldes JG, Berzigotti A, García-Pagan JC. The clinical use of HVPG measurements in chronic liver disease. Nat Rev Gastroenterol Hepatol 2009;6:573-82.

15. Chedid MF, Kruel CRP, Pinto MA, Grezzana-Filho TJM, Leipnitz I, Kruel CDP, Scaffaro LA, Chedid $\mathrm{AD}$. Hepatocellular carcinoma: diagnosis and operative 
management. Arq Bras Cir Dig 2017;30:272-8.

16. Chedid AD, Klein PW, Tiburi MF, Villwock MM, Bassani LE, Chedid MF. Spontaneous rupture of hepatocellular carcinoma with haemoperitoneum: a rare condition in Western countries. HPB (Oxford) 2001;3:227-30.

17. Abraldes JG, Tarantino I, Turnes J, Garcia-Pagan JC, Rodés J, Bosch J. Hemodynamic response to pharmacological treatment of portal hypertension and long-term prognosis of cirrhosis. Hepatology 2003;37:902-8.

18. Abraldes JG, Villanueva C, Bañares R, Aracil C, Catalina MV, Garci A-Pagán JC, Bosch J; Spanish Cooperative Group for Portal Hypertension and Variceal Bleeding. Hepatic venous pressure gradient and prognosis in patients with acute variceal bleeding treated with pharmacologic and endoscopic therapy. J Hepatol 2008;48:229-36.

19. Moitinho E, Escorsell A, Bandi JC, Salmerón JM, GarcíaPagán JC, Rodés J, Bosch J. Prognostic value of early measurements of portal pressure in acute variceal bleeding. Gastroenterology 1999;117:626-31.

20. Monescillo A, Martínez-Lagares F, Ruiz-del-Arbol L, Sierra A, Guevara C, Jiménez E, Marrero JM, Buceta E, Sánchez J, Castellot A, Peñate M, Cruz A, Peña E. Influence of portal hypertension and its early decompression by TIPS placement on the outcome of variceal bleeding. Hepatology 2004;40:793-801.

21. Idilman IS, Li J, Yin M, Venkatesh SK. MR elastography of liver: current status and future perspectives. Abdom Radiol (NY) 2020;45:3444-62.

22. Mueller S, Sandrin L. Liver stiffness: a novel parameter for the diagnosis of liver disease. Hepat Med 2010;2:49-67.

23. Kennedy P, Wagner M, Castéra L, Hong CW, Johnson CL, Sirlin CB, Taouli B. Quantitative elastography methods in liver disease: current evidence and future directions. Radiology 2018;286:738-63.

24. Roehlen N, Crouchet E, Baumert TF. Liver fibrosis: mechanistic concepts and therapeutic perspectives. Cells 2020;9:875.

25. Sugiura N, Karasawa E, Saotome N, Miki M, Matsutani S, Ohto M. Portosystemic collateral shunts originating from the left portal veins in portal hypertension: demonstration by color Doppler flow imaging. J Clin Ultrasound 1992;20:427-32.

26. Chen CH, Wang JH, Lu SN, Tung WC, Hung CH, Lee CM, Changchien CS. Comparison of prevalence for paraumbilical vein patency in patients with viral and alcoholic liver cirrhosis. Am J Gastroenterol 2002;97:2415-8.
27. Morin C, Lafortune M, Pomier G, Robin M, Breton G. Patent paraumbilical vein: anatomic and hemodynamic variants and their clinical importance. Radiology 1992;185:253-6.

28. Kondo T, Maruyama H, Sekimoto T, Shimada T, Takahashi M, Okugawa H, Yokosuka O, Yamaguchi T. Influence of paraumbilical vein patency on the portal hemodynamics of patients with cirrhosis. J Clin Gastroenterol 2014;48:178-83.

29. Sacerdoti D, Bolognesi M, Bombonato G, Gatta A. Paraumbilical vein patency in cirrhosis: effects on hepatic hemodynamics evaluated by Doppler sonography. Hepatology 1995;22:1689-94.

30. Gupta D, Chawla YK, Dhiman RK, Suri S, Dilawari JB. Clinical significance of patent paraumbilical vein in patients with liver cirrhosis. Dig Dis Sci 2000;45:1861-4.

31. Zocco MA, Di Stasio E, De Cristofaro R, Novi M, Ainora ME, Ponziani F, Riccardi L, Lancellotti S, Santoliquido A, Flore R, Pompili M, Rapaccini GL, Tondi P, Gasbarrini GB, Landolfi R, Gasbarrini A. Thrombotic risk factors in patients with liver cirrhosis: correlation with MELD scoring system and portal vein thrombosis development . J Hepatol 2009;51:682-9.

32. Maruyama H, Okugawa H, Takahashi M, Yokosuka O. De novo portal vein thrombosis in virus-related cirrhosis: predictive factors and long-term outcomes. Am J Gastroenterol 2013;108:568-74.

33. Wang Y, Huang CM, Zheng CH, Li P, Xie JW, Wang JB, Lin JX, Lu J. Classification of anatomic variations in the left gastric vein during laparoscopic gastrectomy. Anat Physiol 2013;3:127.

34. Hino S, Kakutani H, Ikeda K, Uchiyama Y, Sumiyama K, Kuramochi A, Kitamura Y, Matsuda K, Arakawa H, Kawamura M, Masuda K, Suzuki H. Hemodynamic assessment of the left gastric vein in patients with esophageal varices with color Doppler EUS: factors affecting development of esophageal varices. Gastrointest Endosc 2002;55:512-17.

35. Widrich WC, Srinivasan M, Semine MC, Robbins AH. Collateral pathways of the left gastric vein in portal hypertension. AJR Am J Roentgenol 1984;142:375-82.

36. Maruyama H, Kobayashi K, Kiyono S, Ogasawara S, Ooka Y, Suzuki E, Chiba T, Kato N. Left gastric veinbased noninvasive test for esophageal varices: a sameday comparison of portal hemodynamic assessment with endoscopic appearance. Clin Transl Gastroenterol 2018;9:154.

37. Matsutani S, Furuse J, Ishii H, Mizumoto H, Kimura K, 
Ohto M. Hemodynamics of the left gastric vein in portal hypertension. Gastroenterology 1993;105:513-8.

38. Hino S, Kakutani H, Ikeda K, Yasue H, Kitamura Y, Sumiyama K, Uchiyama Y, Kuramochi A, Matsuda K, Arakawa H, Hachiya K, Kawamura M, Masuda K, Suzuki H. Hemodynamic analysis of esophageal varices using color Doppler endoscopic ultrasonography to predict recurrence after endoscopic treatment. Endoscopy 2001;33:869-72.

39. Takashi M, Igarashi M, Hino S, Goto N, Okuda K. Chronic portal-systemic encephalopathy with normal portal vein pressure possibly due to noncirrhotic portal fibrosis. Dig Dis Sci 1984;29:669-73.

40. Sugimura T, Tsuji Y, Ibayashi H, Sakai H, Nawata H. Portal-systemic shunting in a patient with normal portal vain pressures and histological evidence of idiopathic portal hypertension. J Gastroenterol Hepatol 1996;11:301-4.

41. Chikamori F, Kuniyoshi N, Shibuya S, Takase Y. Combination treatment of transjugular retrograde obliteration and endoscopic embolization for portosystemic encephalopathy with esophageal varices. Hepatogastroenterology 2004;51:1379-81.

42. Nagaoki Y, Aikata H, Kobayashi T, Fukuhara T, Masaki K, Tanaka M, Naeshiro N, Nakahara T, Honda Y, Miyaki D, Kawaoka T, Takaki S, Tsuge M, Hiramatsu A, Imamura M, Hyogo H, Kawakami Y, Takahashi S, Ochi H, Chayama K. Risk factors for the exacerbation of esophageal varices or portosystemic encephalopathy after sustained virological response with IFN therapy for $\mathrm{HCV}$-related compensated cirrhosis. J Gastroenterol 2013;48:847-55.

43. Pak JM, Lee SS. Glucagon in portal hypertension. J Hepatol 1994;20:825-32.

44. Matsutani S, Maruyama H, Sato G, Fukuzawa T, Mizumoto H, Saisho H. Hemodynamic response of the left gastric vein to glucagon in patients with portal hypertension and esophageal varices. Ultrasound Med Biol 2003;29:13-7.

45. Yu YD, Kim DS, Han JH, Yoon YI. Successful treatment of a patient with diffuse portosplenomesenteric thrombosis using a pericholedochal varix for portal flow reconstruction during deceased donor liver transplantation: a case report. Transplant Proc 2017;49:1202-6.

46. Kimura K, Ohto M, Matsutani S, Furuse J, Hoshino K, Okuda K. Relative frequencies of portosystemic pathways and renal shunt formation through the "posterior" gastric vein: portographic study in 460 patients. Hepatology 1990;12:725-8.
47. Maruyama H, Kamezaki H, Kondo T, Sekimoto T, Takahashi M, Yokosuka O. Sonographic and clinical features of collateral vessels at the splenic hilum in cirrhosis. Clin Radiol 2014;69:e140-5.

48. Maruyama H, Ishihara T, Ishii $\mathrm{H}$, Tsuyuguchi T, Yoshikawa M, Matsutani S, Yokosuka O. Blood flow parameters in the short gastric vein and splenic vein on Doppler ultrasound reflect gastric variceal bleeding. Eur J Radiol 2010;75:e41-5.

49. Fukuda T, Hirota S, Sugimura K. Long-term results of balloon-occluded retrograde transvenous obliteration for the treatment of gastric varices and hepatic encephalopathy. J Vasc Interv Radiol 2001;12:327-36.

50. Gwon DI, Ko GY, Yoon HK, Sung KB, Kim JH, Shin JH, Ko HK, Song HY. Gastric varices and hepatic encephalopathy: treatment with vascular plug and gelatin sponge-assisted retrograde transvenous obliteration--a primary report. Radiology 2013;268:281-7.

51. Ohnishi K, Sato S, Saito M, Terabayashi H, Nakayama T, Saito M, Chin N, Iida S, Nomura F, Okuda K. Clinical and portal hemodynamic features in cirrhotic patients having a large spontaneous splenorenal and/or gastrorenal shunt. Am J Gastroenterol 1986;81:450-5.

52. Maruyama H, Kondo T, Kiyono S, Sekimoto T, Takahashi M, Okugawa H, Yokosuka O. Relationship and interaction between serum sodium concentration and portal hemodynamics in patients with cirrhosis. J Gastroenterol Hepatol 2015;30:1635-42.

53. Quintini C, Spaggiari M, Hashimoto K, Aucejo F, Diago T, Fujiki M, Winans C, D'Amico G, Trenti L, Kelly D, Eghtesad B, Miller C. Safety and effectiveness of renoportal bypass in patients with complete portal vein thrombosis: an analysis of 10 patients. Liver Transpl 2015;21:344-52.

54. Grezzana-Filho TJM, Chedid MF, Chedid AD, BassaniFilho EL, Pereira PF, Leipnitz I, Backes AN, Kruel CRP. How to do liver transplantation using renoportal bypass. ANZ J Surg 2018;88:236-7.

55. D'Amico G, Hassan A, Diago Uso T, Hashmimoto K, Aucejo FN, Fujiki M, Eghtesad B, Sasaki K, Lindenmeyer CC, Miller CM, Quintini C. Renoportal anastomosis in liver transplantation and its impact on patient outcomes: a systematic literature review. Transpl Int 2019;32:117-27.

56. Wachsberg RH. Inferior mesenteric vein: gray-scale and Doppler sonographic findings in normal subjects and in patients with portal hypertension. AJR Am J Roentgenol 2005;184:481-6.

57. Warren WD, Milliken WJ Jr, Henderson JM, Wright 
L, Kutner M, Smith RB 3rd, Fulenwider JT, Salam AA, Galambos JT. Ten years of portal hypertensive surgery at Emory: results and new perspective. Ann Surg 1982;195:530-42.

58. Graf O, Boland GW, Kaufman JA, Warshaw AL, Fernandez del Castillo C, Mueller PR. Anatomic variants of mesenteric veins: depiction with helical CT venography. AJR Am J Roentgenol 1997;168:1209-13.

59. Sakaguchi T, Suzuki S, Morita Y, Oishi K, Suzuki A, Fukumoto K, Inaba K, Kamiya K, Ota M, Setoguchi T, Takehara Y, Nasu H, Nakamura S, Konno H. Analysis of anatomic variants of mesenteric veins by 3 -dimensional portography using multidetector-row computed tomography. Am J Surg 2010;200:15-22.

60. Ito K, Blasbalg R, Hussain SM, Mitchell DG. Portal vein and its tributaries: evaluation with thin-section threedimensional contrast-enhanced dynamic fat-suppressed MR imaging. Radiology 2000;215:381-6.

61. Zuberi FF, Zuberi BF, Khan MA, Khan MH. Frequency of rectal varices in patients with cirrhosis. J Coll Physicians Surg Pak 2004;14:94-7.

62. Chawla Y, Dilawari JB. Anorectal varices--their frequency in cirrhotic and non-cirrhotic portal hypertension. Gut 1991;32:309-11.

63. Heaton ND, Davenport M, Howard ER. Incidence of haemorrhoids and anorectal varices in children with portal hypertension. Br J Surg 1993;80:616-8.

64. Wang TF, Lee FY, Tsai YT, Lee SD, Wang SS, Hsia HC, Lin WJ, Lin HC, Lai KH, Chan CY, Lo KJ. Relationship of portal pressure, anorectal varices and hemorrhoids in cirrhotic patients. J Hepatol 1992;15:170-3.

65. Misra SP, Dwivedi M, Misra V. Prevalence and factors influencing hemorrhoids, anorectal varices, and colopathy in patients with portal hypertension. Endoscopy 1996;28:340-5.

66. Shudo R, Yazaki Y, Sakurai S, Uenishi H, Yamada H, Sugawara K. Clinical study comparing bleeding and nonbleeding rectal varices. Endoscopy 2002;34:189-94.

67. Maruyama H, Kamezaki H, Kondo T, Sekimoto T, Shimada T, Takahashi M, Okugawa H, Yokosuka O. Effects of inferior mesenteric vein flow in patients with cirrhosis. Clin Gastroenterol Hepatol 2013;11:1648-54.

68. Hashizume M, Tanoue K, Ohta M, Ueno K, Sugimachi K, Kashiwagi M, Sueishi K. Vascular anatomy of duodenal varices: angiographic and histopathological assessments. Am J Gastroenterol 1993;88:1942-5.

69. Bhagani S, Winters C, Moreea S. Duodenal variceal bleed: an unusual cause of upper gastrointestinal bleed and a difficult diagnosis to make. BMJ Case Rep 2017;2017:bcr2016218669.

70. McLoughlin RF, Dashefsky SM, Cooperberg PL, Mathieson JR. Spontaneous portal-right renal vein shunt in portal hypertension. J Ultrasound Med 1995;14:959-61.

71. Sabol Pušić M, Budimir I, Dorosulić Z, Ostrički B, Nikolić M, Lovrenčić Prpić G, Sreter KB. Portal systemic shunt between the hepatic portal vein and right renal vein in a patient with multifocal hepatocellular carcinoma: case report. J Clin Ultrasound 2017;45:524-7.

72. Yagisawa H, Ishida H, Komatsuda T, Furukawa K, Yamada M, Ohno H, Sato A, Miyauchi T. Portal-systemic shunt through the right renal vein developing following portal tumor thrombus. J Med Ultrason (2001) 2006;33:181-4.

73. Kikuchi H, Noguchi M, Akashi H, Noda S. Spontaneous shunt between the superior mesenteric vein and the right renal vein caused by portal hypertension. J Urol 2001;165:1615-6.

74. Chedid MF, Zahler S, Chedid AD, Leipnitz I, Prediger JE, Giampaoli AZD, Lopes BB, Kruel CRP, Grezzana-Filho TJM. Liver transplantation in the setting of a spontaneous shunt between superior mesenteric vein and right renal vein. Ann Hepatol 2020;19:335-7.

75. Norton ID, Andrews JC, Kamath PS. Management of ectopic varices. Hepatology 1998;28:1154-8.

76. Uhlenhopp D, Olson K, Sunkara T. A novel approach for management of bleeding stomal varices: a case report of ultrasound-guided percutaneous sclerotherapy. J Investig Med High Impact Case Rep 2020;8:2324709620904569.

77. Tran-Harding K, Winkler M, Raissi D. Bleeding stomal varices in portal hypertension. Radiol Case Rep 2018;13:356-60.

78. Spier BJ, Fayyad AA, Lucey MR, Johnson EA, Wojtowycz M, Rikkers L, Harms BA, Reichelderfer M. Bleeding stomal varices: case series and systematic review of the literature. Clin Gastroenterol Hepatol 2008;6:346-52.

79. Shapir J, Rubin J. CT appearance of the inferior mesenteric vein. J Comput Assist Tomogr. 1984;8:877-80.

80. Akpinar E, Turkbey B, Karcaaltincaba M, Karaosmanoglu D, Akata D. MDCT of inferior mesenteric vein: normal anatomy and pathology. Clin Radiol 2008;63:819-23.

81. Chen S, Li X, Wei B, Tong H, Zhang MG, Huang ZY, Cao JW, Tang CW. Recurrent variceal bleeding and shunt patency: prospective randomized controlled trial of transjugular intrahepatic portosystemic shunt alone or combined with coronary vein embolization. Radiology 2013;268:900-6.

82. Cho SY, Kim SH, Lee KW, Park SJ, Han SS, Kim YK. 
Ligation of left renal vein as a salvage procedure for splenorenal shunt after living donor liver transplantation: a case report. Transplant Proc 2009;41:4243-5.

83. Slater RR, Jabbour N, Abbass AA, Patil V, Hundley J, Kazimi M, Kim D, Yoshida A, Abouljoud M. Left renal vein ligation: a technique to mitigate low portal flow from splenic vein siphon during liver transplantation. Am J Transplant 2011;11:1743-7.

84. Mukund A, Chalamarla LK, Singla N, Shasthry SM, Sarin SK. Intractable hepatic encephalopathy in cirrhotic patients: mid-term efficacy of balloon-occluded retrograde portosystemic shunt obliteration. Eur Radiol 2020;30:3462-72.

85. Maruyama H, Kondo T, Kiyono S, Sekimoto T, Takahashi $\mathrm{M}$, Yokosuka O. Influence of splenorenal shunt on longterm outcomes in cirrhosis. Scand J Gastroenterol 2015;50:593-600.

86. Tarantino G, Citro V, Conca P, Riccio A, Tarantino M, Capone D, Cirillo M, Lobello R, Iaccarino V. What are the implications of the spontaneous spleno-renal shunts in liver cirrhosis? BMC Gastroenterology 2009;9:89.

87. Thiele M, Hugger MB, Kim Y, Rautou PE, Elkrief L, Jansen C, Verlinden W, Allegretti G, Israelsen M, Stefanescu H, Piscaglia F, García-Pagán JC, Franque S, Berzigotti A, Castera L, Jeong WK, Trebicka J, Krag A. 2D shear wave liver elastography by Aixplorer to detect portal hypertension in cirrhosis: an individual patient data meta-analysis. Liver Int 2020;40:1435-46.

88. Ferraioli G, Wong VW, Castera L, Berzigotti A, Sporea I, Dietrich CF, Choi BI, Wilson SR, Kudo M, Barr RG. Liver ultrasound elastography: an update to the world federation for ultrasound in medicine and biology guidelines and recommendations. Ultrasound Med Biol 2018;44:2419-40.

89. Qi X, Berzigotti A, Cardenas A, Sarin SK. Emerging non-invasive approaches for diagnosis and monitoring of portal hypertension. Lancet Gastroenterol Hepatol 2018;3:708-19.

Cite this article as: Maruyama $\mathrm{H}$, Shiina S. Collaterals in portal hypertension: anatomy and clinical relevance. Quant Imaging Med Surg 2021;11(8):3867-3881. doi: 10.21037/qims-201328
90. Takahashi H, Suzuki M, Shigefuku R, Okano M, Hiraishi T, Takagi R, Noguchi Y, Hattori N, Hatsugai M, Nakahara K, Okamoto M, Kobayashi M, Ikeda H, Fukuda Y, Nagase Y, Ishii T, Matsunaga K, Matsumoto N, Okuse C, Sase $\mathrm{S}$, Itoh F. Xenon computed tomography can evaluate the improvement of hepatic hemodynamics before and after endoscopic injection sclerotherapy. J Gastroenterol 2013;48:1353-61.

91. Stankovic Z, Allen BD, Garcia J, Jarvis KB, Markl M. 4D flow imaging with MRI. Cardiovasc Diagn Ther 2014;4:173-92.

92. Stankovic Z, Csatari Z, Deibert P, Euringer W, Blanke P, Kreisel W, Abdullah Zadeh Z, Kallfass F, Langer M, Markl M. Normal and altered three-dimensional portal venous hemodynamics in patients with liver cirrhosis. Radiology 2012;262:862-73.

93. Roldán-Alzate A, Frydrychowicz A, Niespodzany E, Landgraf BR, Johnson KM, Wieben O, Reeder SB. In vivo validation of $4 \mathrm{D}$ flow MRI for assessing the hemodynamics of portal hypertension. J Magn Reson Imaging 2013;37:1100-8.

94. Simón-Talero M, Roccarina D, Martínez J, Lampichler K, Baiges A, Low G, Llop E, Praktiknjo M, Maurer MH, Zipprich A, Triolo M, Vangrinsven G, Garcia-Martinez R, Dam A, Majumdar A, Picón C, Toth D, Darnell A, Abraldes JG, Lopez M, Kukuk G, Krag A, Bañares R, Laleman W, La Mura V, Ripoll C, Berzigotti A, Trebicka J, Calleja JL, Tandon P, Hernandez-Gea V, Reiberger T, Albillos A, Tsochatzis EA, Augustin S, Genescà J; Baveno VI-SPSS group from the Baveno Cooperation. Association between portosystemic shunts and increased complications and mortality in patients with cirrhosis. Gastroenterology 2018;154:1694-705.e4.

95. Pillai AK, Andring B, Patel A, Trimmer C, Kalva SP. Portal hypertension: a review of portosystemic collateral pathways and endovascular interventions. Clin Radiol 2015;70:1047-59. 